\title{
Characterization in expected working environments of recyclable fire-resistant materials
}

\author{
Giulia De Aloysio ${ }^{1 *}$, Mattia Morganti ${ }^{1}$, Luca Laghi $^{1}$, Matteo Scafè ${ }^{2}$,Enrico Leoni ${ }^{2}$, \\ Claudio Mingazzini ${ }^{2}$, Stefano Bassi $^{3}$ \\ ${ }^{1}$ CertiMaC, 48018 Faenza RA, Italy \\ ${ }^{2}$ ENEA SSPT-PROMAS-TEMAF, 48018 Faenza RA, Italy \\ ${ }^{3}$ CNR-ISTEC, 48018 Faenza RA, Italy
}

\begin{abstract}
This study focuses on the development of multi-material solutions for fire-resistant structural materials for transport and thermal insulation in the construction field. Special attention was paid to combining recyclable and bio-mass derived raw materials without interfering with an easy end-of-life separation, recycling and reuse. Fire-resistant biomass derived resins were associated with basalt derived Mineral Fibres (BDMF) in the form of prepregs, which were studied as semi-finished materials. Fireresistance was obtained by associating these prepregs with thin gres tiles in the case of fire-resistant thermal insulating facades and with aluminum layers (giving origin to Fibre Metal Laminates-FML) in the case of structural components for transport applications. Thermophysical characterization of the solutions was carried out to assess both thermal conductivity and thermal diffusivity. Fire resistance tests were performed on FML to determine the number of Al layers needed to ensure fire resistance. Results suggest that fire resistance depends primarily on the number of $\mathrm{Al}$ layers, rather than on their thickness. Accelerated ageing tests (salty mist and freeze-thaw) were executed to predict durability in the expected working conditions. Results suggest a durability issue in FML with preceramic interface in salty environments.
\end{abstract}

\section{Introduction}

In recent times it has become essential to improve the properties of materials - strength, stiffness and density - while reducing costs and improving sustainability. In particular, in both the transport and construction sectors, the recyclability of fire-resistant and thermal insulating materials, combined with satisfying durability and low-cost requirements, are well known open issues. Composite materials have been developed to satisfy these needs in a wide range of applications. [1]

One of the most effective methods for improving polymer properties consists in creating polymer matrix-based composites (PMCs) whose matrix can be made up of either organic or inorganic polymer and where short or continuous fibres ensure improved lightweight, high stiffness, high specific strength and good resistance to fatigue [2].

\footnotetext{
* Corresponding author: g.dealoysio@certimac.it
} 
However, the main technological limit for the application of polymer composites (PMC) is the insufficient resistance to temperature, while for ceramic matrix composites (CMC) the main limitations are as follows:

- excessive costs,

- $\quad$ long time for manufacturing;

- high production complexity.

In order to overcome these shortcomings, the FIREMAT-Project-FIRE resistant MATerials \& composites (https://firemat.it/) is aimed at developing new materials and processes, focusing on their integration into multi-material solutions, and on the engineering and development of design methodologies aimed at ensuring sustainable production.

The FIREMAT project develops long and short Fibre-reinforced composites for high temperature and fireproof applications for both exhaust pipes and fireproof insulating panels. These Fibre-reinforced composites will guarantee fire performance comparable to ceramic materials but also the lightness and ease of production typical of polymeric composites. In particular, two sustainable macro-types of heat-resistant materials were produced as follows:

- $\quad$ fireproof composites (Fibre Metal Laminates- FML) reinforced with basalt fibre in form of recyclable, fireproof and thermal-insulating panels;

- composites reinforced with long or short carbon fibres (virgin/recycled) with a nano-structured refractory matrix for thermal barriers with working temperatures up to $800^{\circ} \mathrm{C}$.

In this framework, fire-resistant biomass derived resins were associated with basalt derived Mineral Fibres (BDMF) in the form of prepregs, which were studied as semi-finished materials for fire-resistant thermal insulating facades and for structural components for transport applications.

The fire-resistance of multi-materials was obtained by associating these prepregs with thin $(3-4 \mathrm{~mm})$ gres tiles in the construction sector and with aluminum layers in the transport sector. The paper describes the results of the development and testing of the two innovative fibre reinforced composites focusing on the relevant thermal, mechanical and fire resistance properties which could allow the wide exploitation of such materials.

\section{Multi-material solutions developed}

As regards the structure of the multi-material solutions, the fire-resistant multi-material obtained (Fig. 1) by associating prepregs with gres tiles is formed by three different layers as follows:

- $\quad$ basalt felt (10 mm thickness)

- biomass derived resins and basalt fabric prepreg

- $\quad$ gres tile $(3 \mathrm{~mm})$.

The multi-material was produced by single-step warm pressing at $150-200^{\circ} \mathrm{C}$. In this context, careful assessment of the curing process parameters of the resins and prepregs is essential to avoid defects in the final structural properties [3]. Curing time depends on the type of prepreg, which also acts as "adhesive" between the layers, and on temperature. In particular, higher temperatures result in lower curing time and at least $10 \mathrm{~min}$ appears to be necessary for the curing time. 


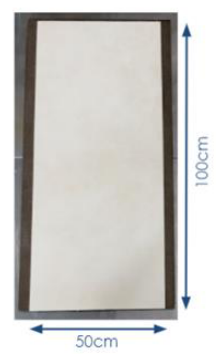

Fig. 1. fire-resistant multi-material obtained by associating prepregs with gres tiles

The FML is composed of the following layers:

- aluminium alloy which was modified with surface primer or preceramic interface

- biomass derived fire-retardant resin associated with basalt fabric, in the form of a ready-to-use prepreg.

The number of the layers and their stacking order depends on the desired final object and mechanical properties. The structural properties of the FML were achieved through a presscuring cycle at $150-200^{\circ} \mathrm{C}$. The curing time for the process that involves the prepreg and the Al sizing or preceramic interface is of at least $10 \mathrm{~min}$.

\section{Experimental Methods}

Different characterization techniques were employed to assess the thermophysical, mechanical and fire-resistance properties of the developed solutions.

The thermophysical characterization of the fireproof composites (FML) was carried out by means of the Light Flash Method - LFA 467 HT ${ }^{\circledR}$ Hyper Flash NETZSCH - in order to investigate the behaviour of the solutions through the assessment of thermal diffusivity, specific heat and thermal conductivity in the temperature range between $25^{\circ} \mathrm{C}$ and $500^{\circ} \mathrm{C}$.

The LFA method allows the direct determination of thermal diffusivity and, through the Software Proteus ${ }^{\circledR}$, the indirect determination of specific heat and thermal conductivity, with known sample density. The specific heat of the sample was determined by comparing its temperature increase with that of a Pyroceram reference sample in order to assess the absorbed energy. Thermal diffusivity is determined by conducting a mathematical analysis of the measured temperature increase/time function, as explained by Parker et al. [4]. On the basis of thermal diffusivity, specific heat and density values, it is possible to calculate thermal conductivity $(\lambda)$ as shown in Eq. 1.

$$
\lambda(T)=\alpha(T) \times \rho(T) \times c_{p}(T)
$$

Where $c_{p}$ is the specific heat and $\rho$ is the bulk density of the sample.

The thermophysical characterization of the fire-resistance multi-material obtained by associating prepregs with thin $(3-4 \mathrm{~mm})$ gres tiles was performed by means of the Heat Flow Meter HFM 436 Lambda NETZSCH in order to assess the thermal conductivity of the solutions for the construction sector under steady state conditions. Thermal conductivity was determined at an average temperature of $10^{\circ} \mathrm{C}$ on squares samples. In a heat flow meter (HFM), the sample is placed between two plates heated at different temperatures giving origin to a heat flow (Q) through the samples. Thermal resistance is calculated on the basis of heat flow and sample thickness. Thermal conductivity $(\lambda)$ is calculated on the basis of the average heat flux and the thermal resistance R according to Fourier's Law [5].

Fire-proof resistance was assessed through the cone-calorimeter FTT compliant with ISO 5660-1:2015 to study and compare the fire behaviour of the different solutions developed by 
gathering data on ignition time, mass loss, combustion products, heat release rate (HRR) and other parameters associated with the burning properties of the sample. The heat release rate is measured on the basis of Huggett's principle [6]. In the cone-calorimeter the sample surface is exposed to nearly uniform heat fluxes, which are produced by a conical radiant heater. The cone-calorimetry tests allow verifying the combustibility classification of the developed solutions according to EN ISO 1182.

Pull-off tests were carried out to verify the adhesion of the prepreg to other materials (ceramic tile in particular). Moreover, bending tests were performed to obtain the mechanical strength data necessary for subsequent finite element analysis.

The mechanical properties of the solutions before and after ageing were evaluated according to ASTM D3039 standard by means of an MTS 70 tf servo-hydraulic testing machine for evaluation tensile behaviour of materials and systems. Maximum strength and Young's modulus of the FML solutions with or without primer and of the FMLs with preceramic interface before and after $1000 \mathrm{~h}$ ageing in salt spray were assessed. The ageing in salty spray environment was carried out according to EN ISO 9227 by means of an ACS dry corrosion test cabinet (Angelantoni Test Technologies). The fully automatic climatic chamber operates between $23^{\circ} \mathrm{C}$ and $55^{\circ} \mathrm{C}$ and between 50 and $99 \% \mathrm{RH}$ with the option of accelerated ageing in neutral, acetic and cupric acetic salt spray. The apparatus is characterized by a volume of $900 \mathrm{~L}$ and allows testing the ability of materials to resist in aggressive saline environment, acidic or basic solutions.

Furthermore, pull-off tests and three-point bending tests were carried out on ventilated façade panels through the above-mentioned MTS apparatus before and after ageing. A specific fully automatic climatic chamber (Votsch Industrietechnik VBT 03/1000/S) for artificial freeze/thaw ageing was employed for the determination of the ageing effect by freeze/thaw cycles on the panels according to ETAG $004 \mathrm{cl}$. 5.1.3.2.2.

\section{Results and Discussion}

This section shows the results of the characterizations carried out on the developed solutions.

\subsection{Thermophysical characterizations}

One of the most common techniques used to evaluate the thermal properties of FMLs is the Laser/Light Flash method as in [7]. Fig.2 shows an example of the FML samples employed for the characterization. Three circular samples of fire-resistant multi-material obtained by associating prepregs with aluminum were cored from rectangular slabs to determine thermal diffusivity, specific heat and thermal conductivity through LFA shown in Figs. 3-5. The samples had average density of $1747 \mathrm{~kg} / \mathrm{m}^{3}$, average thickness of $0.765 \mathrm{~mm}$ and a diameter of about $12.7 \mathrm{~mm}$. The parameters employed for the LFA experimentations are reported in Table 1.

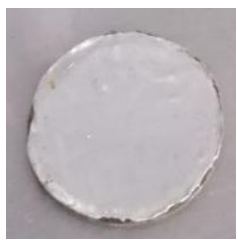

Fig. 2. Sample employed for the LFA experimentation 
Table 1. Parameters employed for the experimentation

\begin{tabular}{|c|c|}
\hline Test Parameters & Value \\
\hline Atmosphere & $\mathrm{Ar}$ \\
\hline Gas rate flow & $50 \mathrm{ml} / \mathrm{min}$ \\
\hline Heating rate & $4 \mathrm{~K} / \mathrm{min}$ \\
\hline Pulse Width & $600 \mu \mathrm{s}$ \\
\hline Post-analysis Model & Standard \\
\hline
\end{tabular}

Five shots were performed for each temperature point in order to ensure the repeatability of the results.
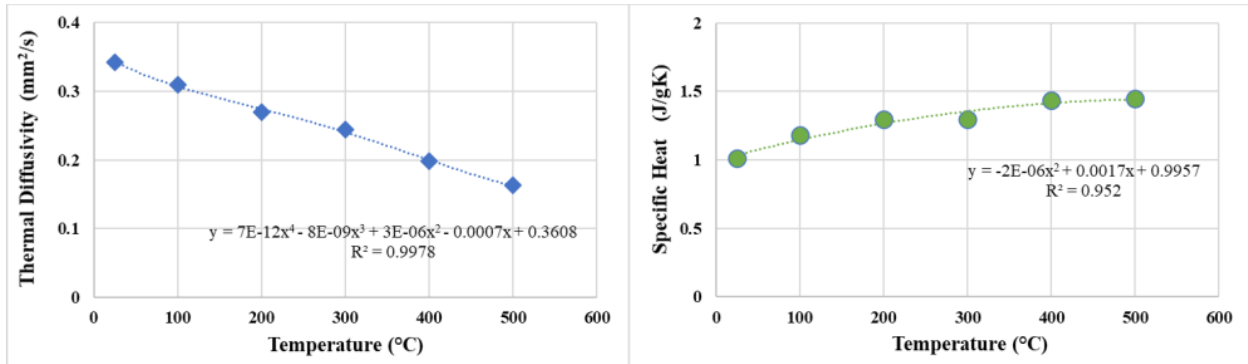

Fig. 3. Thermal diffusivity (left hand side) and specific heat (right hand side) of the tested samplesAverage values of the three samples

Thermal diffusivity shows a decreasing trend when temperature increases, while specific heat increases with increasing temperature. The specific heat trend (Fig.3) is consistent with the literature findings on FMLs [8]. Thermal conductivity reflects the increasing specific heat trend at low temperatures - up to $100{ }^{\circ} \mathrm{C}$ as in [7] - while it decreases over $100{ }^{\circ} \mathrm{C}$, maybe due to the increasing influence of the resins on the thermal behaviour of the solutions.

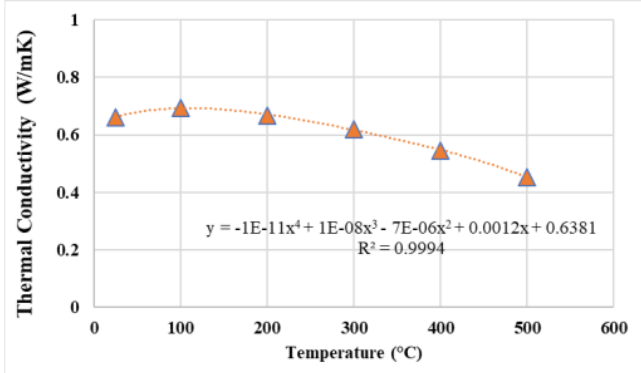

Fig. 4. Thermal conductivity of the tested samples-Average values of the three samples

As regards insulating panels for ventilated facades, the thermal conductivity was measured considering two different durations (6 and 12 minutes) of the warm pressing process marked as Solution A and Solution B in Fig.5. The results of both measurements are of $0.048 \mathrm{~W} / \mathrm{mK}$ and appear not to be affected by the duration of the warm pressing process. Moreover, they represent a good compromise between the thermal conductivity of fibre glass [9] and gres tiles [10]. 


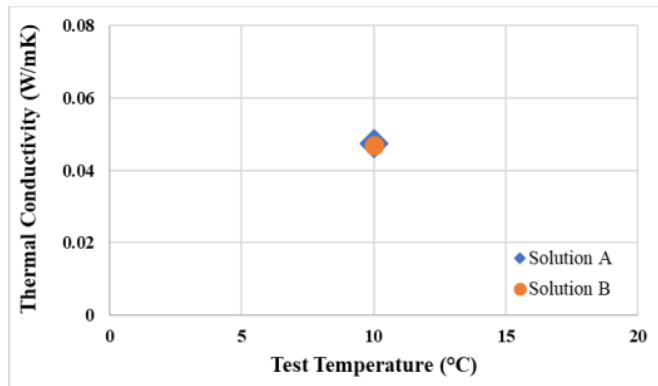

Fig. 5. Thermal conductivity of the tested samples-Average values of the three samples

\subsection{Fire-resistance characterization}

Table 3 shows the results of the fire-resistance tests carried out on several FML solutions made up of Al layers of different thicknesses as in Fig.6. The fire-resistance tests were executed on $100 \times 100 \mathrm{~mm}^{2}$ samples by considering the flame ignition system (electric arc) deactivated during the non-combustibility tests $(30 \mathrm{~min})$ and activated during the Single Burning Item tests $(10 \mathrm{~min})$. The weight of the samples was measured before and after the test and the samples were exposed to a heat flow of $46 \mathrm{~kW} / \mathrm{m}^{2}$, corresponding to a temperature of $750 \pm 5^{\circ} \mathrm{C}$.

FMLs: some images before (1) and after (2) performing the fire test

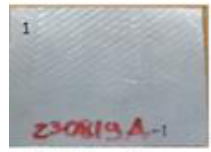

Al thickness $0.1 \mathrm{~mm}$

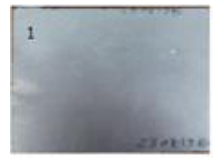

Al thickness $0.02 \mathrm{~mm}$
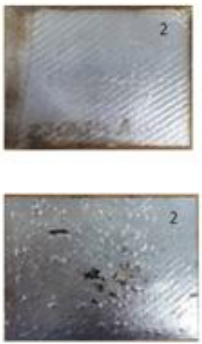

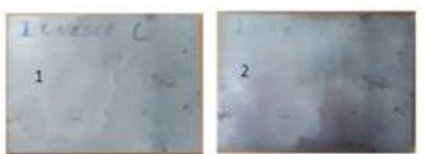

Al thickness $0.3 \mathrm{~mm}$

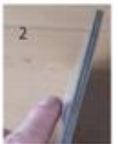

Fig.6. Pictures of FML before and after cone-calorimeter tests

According to the European standards, several FML solutions meet the class A1 range parameters shown in Table 2. Results suggest that fire resistance depends primarily on the number of $\mathrm{Al}$ layers, rather than on their thickness (tested in the range 20-300 microns).

Table 2. Parameters related to the European class A reaction to fire performance

\begin{tabular}{|c|c|c|}
\hline Class A1 & \multicolumn{2}{|c|}{ Class A2 } \\
\hline EN ISO 1182 & EN ISO 1182 & EN ISO 13823 \\
\hline$\Delta \mathbf{T} \leq 30^{\circ} \mathrm{C}$ & $\Delta \mathrm{T} \leq 50^{\circ} \mathrm{C}$ & FIGRA $_{0,2 \mathrm{MJ}} \leq 120 \mathrm{~W} / \mathrm{s}$ \\
\hline$\Delta \mathbf{m} \leq 50 \%$ & $\Delta \mathrm{m} \leq 50 \%$ & $\mathrm{THR} \leq 7,5 \mathrm{MJ} / \mathrm{m}^{2}$ \\
\hline $\mathrm{t}_{\text {flameou }}^{\dagger} \mathrm{t} 0 \mathrm{~s}$ & $\mathrm{t}_{\text {flameout }} \leq 20 \mathrm{~s}$ & \\
\hline
\end{tabular}

\footnotetext{
$\dagger$ tof flameout: time when the flame goes out
} 
Table 3. Results of the cone-calorimeter test

\begin{tabular}{|c|c|c|c|c|c|c|c|c|c|c|c|}
\hline & $\mathbf{A}$ & $\mathbf{B}$ & $\mathbf{C}$ & $\mathbf{D}$ & $\mathbf{E}$ & $\mathbf{F}$ & $\mathbf{G}$ & $\mathbf{H}$ & $\mathbf{I}$ & $\mathbf{L}$ & $\mathbf{M}$ \\
\hline$\Delta \mathbf{T}\left[{ }^{\circ} \mathbf{C}\right]$ & 9.25 & 12.5 & 14.9 & 13.4 & 14.9 & 12.2 & 11.4 & 12.7 & 13.6 & 11.4 & 12.4 \\
\hline$\Delta \mathbf{m}[\%]$ & 0.95 & 0.85 & 4.5 & 1.45 & 1.4 & 12.6 & 8.0 & 10.5 & 10.4 & 3.0 & 6.4 \\
\hline $\begin{array}{c}\text { t of flame } \\
{[\mathbf{[ s ]}}\end{array}$ & - & - & - & - & - & 92.5 & - & 174.0 & 249.0 & - & - \\
\hline $\begin{array}{c}\mathbf{H R R}^{\ddagger} \mathbf{p} \text { peak } \\
{\left[\mathbf{k W} / \mathbf{m}^{2}\right]}\end{array}$ & 38.1 & 18 & 1107.5 & 12.3 & 5.2 & 79.9 & - & 62.1 & 29.8 & 2.2 & 1.7 \\
\hline
\end{tabular}

\subsection{Mechanical characterization}

The standard test for tensile properties was carried out, according to ASTM D3039, on the FMLs to determine the mechanical properties and their degradation after ageing effect by salt spray. The spray temperature was set at $35^{\circ} \mathrm{C}$, the relativity humidity was of $95 \%$ and a constant rain gauge ranging from 0.5 to $3.0 \mathrm{~cm}^{3} / \mathrm{h}$ was considered for the experimentation. The $\mathrm{pH}$ of the environment ranged from 6.9 to 7.2 while the salinity was ensured by a solution concentration of $50 \mathrm{~g} /$ litre of $\mathrm{NaCl}$ in deionized $\mathrm{H}_{2} \mathrm{O}$. The samples were visually checked once a week throughout the testing period.

Results in salty mist show a durability issue in FML with preceramic interface in salty environments. This suggests that more suitable types of primers (or different preceramic interface) should be investigated in these working conditions. Moreover, the reduction of the mechanical properties after exposure in salty environments is consistent with literature findings on FMLs [11].

Freeze thaw resistance was evaluated on ventilated façade panels according to ETAG $004 \mathrm{cl}$. 5.1.3.2.2 after 30 cycles (each cycle: 24 hours) between $-20^{\circ} \mathrm{C}$ and $23^{\circ} \mathrm{C}$ by immersion. The Pull-off samples size was of $80 \times 80 \mathrm{~mm}^{2}$ while the Three-point bending samples size was of $260 \times 80 \mathrm{~mm}^{2}$.

Table 4. Results of the standard test of the tensile properties

\begin{tabular}{|c|c|c|c|}
\hline ASTM D3039 & $\begin{array}{c}\text { Max Stress } \\
{[\text { MPa] }}\end{array}$ & $\begin{array}{c}\text { Young's Modulus } \\
\text { [GPa] }\end{array}$ & $\begin{array}{c}\text { Failure typical } \\
\text { mode }\end{array}$ \\
\hline FML w/o primer & $443 \pm 5$ & $22.2 \pm 0.3$ & DWB \\
\hline $\begin{array}{c}\text { Aged FML w/o } \\
\text { primer }\end{array}$ & $415 \pm 9$ & $22.9 \pm 0.3$ & AAB/AAT \\
\hline $\begin{array}{c}\text { FML with preceramic } \\
\text { interface }\end{array}$ & $524 \pm 32$ & $21.3 \pm 0.9$ & LAT/LAB \\
\hline $\begin{array}{c}\text { Aged FML with } \\
\text { preceramic interface }\end{array}$ & $356 \pm 4$ & $20.4 \pm 0.3$ & AAT/AWB/LAB \\
\hline
\end{tabular}

Table 5. Results of the pull-off and three-point bending tests

\begin{tabular}{|c|c|c|c|}
\hline & $\begin{array}{c}\text { Unconditioned } \\
\text { gres }\end{array}$ & $\begin{array}{c}\text { Unconditioned } \\
\text { gres + prepreg }\end{array}$ & $\begin{array}{c}\text { Freeze/thaw conditioned } \\
\text { gres + prepreg }\end{array}$ \\
\hline Pull-off test & $/$ & $4,3 \mathrm{MPa}$ & $3,2 \mathrm{MPa}$ \\
\hline $\begin{array}{c}\text { Three-point bending } \\
\text { test }\end{array}$ & $\begin{array}{c}\text { strength: } 1605 \mathrm{~N} \\
\text { modulus: } 59,4 \mathrm{MPa}\end{array}$ & $\begin{array}{c}\text { strength: } 1781 \mathrm{~N} \\
\text { modulus: } 55,0 \mathrm{MPa}\end{array}$ & $\begin{array}{c}\text { strength: } 1604 \mathrm{~N} \\
\text { modulus: } 51,1 \mathrm{MPa}\end{array}$ \\
\hline & $\begin{array}{c}\text { Unconditioned } \\
\text { basalt felt }\end{array}$ & $\begin{array}{c}\text { Unconditioned } \\
\text { basalt felt + prepreg }\end{array}$ & $\begin{array}{c}\text { Freeze/thaw conditioned } \\
\text { basalt felt + prepreg }\end{array}$ \\
\hline Pull-off test & $0,05 \mathrm{MPa}$ & $0,03 \mathrm{MPa}$ & $0,02 \mathrm{MPa}$ \\
\hline $\begin{array}{l}\text { Three-point bending } \\
\text { test }\end{array}$ & $\begin{array}{c}\text { strength: } 107 \mathrm{~N} \\
\text { modulus: } 2,7 \mathrm{MPa}\end{array}$ & $\begin{array}{c}\text { strength: } 207 \mathrm{~N} \\
\text { modulus: } 4,8 \mathrm{MPa}\end{array}$ & $\begin{array}{c}\text { strength: } 175 \mathrm{~N} \\
\text { modulus: } 3,8 \mathrm{MPa}\end{array}$ \\
\hline
\end{tabular}

$\$$ t of flame: time of flame $=$ duration of sustained flaming [s] (duration of flaming)

$\S$ HRR: represents the rate of heat generation by fire 


\section{Conclusions}

Thermophysical characterization was carried out with different technologies in order to assess both the thermal diffusivity and the insulating ability of the FML solutions for the transport sector and of the insulating panels for ventilated facades.

Fire resistance tests were performed on FML to determine the number of Al layers needed to ensure fire resistance in the transport sector. Results suggested that fire resistance depends primarily on the number of $\mathrm{Al}$ layers, rather than on their thickness.

Accelerated ageing tests (salty mist and freeze thaw) were executed in order to predict durability in the expected working conditions. Results showed a durability issue in FML with preceramic interface in salty environments. This suggests that more suitable types of primers (or different preceramic interface) should be investigated in these working conditions.

This project is co-financed under the European Regional Development Fund (POR-FESR) 20142020 of the Emilia-Romagna Region.

\section{References}

1. D. Kumar Rajak, D. D. Pagar, P. L. Menezes, E. Linul, Poly., 11, 1667, (2019) doi:10.3390/polym11101667

2. I. O. Oladele, T. F. Omotosho, A. A. Adediran, Int. J. of Poly., 2020, Article ID 8834518, (2020)

3. L.Giorgini, L. Mazzocchetti, T. Benelli, G. Minak, E. Poodts, E. Dolcini, Polym. Compos., 34:1506-1514, (2013)

4. W. J. Parker, R. J. Jenkins, C. P. Butler, G. L. Abbott, Journal of Applied Physics 32, 1679 (1961)

5. Y, A. Çengel, P. Ricciardi, Termodinamica e trasmissione del calore, Mc Graw Hill Education, New York (2013)

6. C.Hugget, Fire and Materials, 4 (2): 61-65 (1980)

7. Mutnuri, Bhyrav, "Thermal conductivity characterization of composite materials" Graduate Theses, Dissertations, and Problem Reports. 1715, (2006), available at https://researchrepository.wvu.edu/etd/1715

8. M. Hagenbeek, Characterisation of fibre metal laminates under thermomechanical loadings, Doctoral Thesis, TU Delft, (2005)

9. R. Levinson, H. Akbari, L. Gartland. Impact of the Temperature Dependency of Fiberglass Insulation R-Value on Cooling Energy Use in Buildings, in Proceedings of the 1996 ACEEE Summer Study on Energy Efficiency in Buildings, Conference Proceedings, United States (1996)

10. C. Efftinga, S. Güthsb, O. E. Alarcona, Evaluation of the Thermal Comfort of Ceramic Floor Tiles, Mat. Res., 10, No. 3, 301-307 (2007)

11. S. Singh, S. Angra, Eng. Sci. and Tech., an Int.J., 21, Issue 1 (2018) 